\title{
Study on the Characteristics and Techniques of Humorous Language in Fortress Besieged
}

\section{Xiuli Wang}

Sichuan Agricultural University, Ya’an, Sichuan, 625014

Keywords: Fortress Besieged, Humorous Language, Features, Tips

\begin{abstract}
Fortress Besieged is a novels with a combination of banter, seriousness and absurdity. The novel enjoys a high reputation in the world literary world with its excellent humorous language. In the text, the author flexibly uses various means of expression such as voice, grammar, rhetoric and context to form a humorous linguistic characteristic of unconventional, witty, and philosophical implication.
\end{abstract}

\section{Introduction}

Mr. Qian's "Fortress Besieged" is a unique novel based on the morbid deformity of the Chinese middle and upper-class intellectuals in the world. Since his publication, he has enjoyed world literary worlds with his excellent humorous satire language style High reputation, known as "the new Scholars". The construction of "Fortress Besieged" sense of humorous language art style can not be separated from the text carrier - the communication of language, which is reflected in the clever combination and flexible use of languages in many aspects such as speech, grammar, pragmatics and context, and various means of expression, A flexible form of humorous art that exudes its wisdom and inspiration.

\section{2. "Fortress Besieged" humorous language features}

Humorous language is a human knowledge, talent, wisdom, inspiration in the language of the flash, is a humorous and meaningful language expression. "Fortress Besieged" is good at breaking the language convention, making use of words ambiguity, collocation, metaphor of rhetoric and other means to make the logical and logical variations, thus revealing unconventional linguistic effects of language expression. Such as:

When writing the name of a foreigner or a thing into a Chinese work, it is usually transliterated using the method of transliteration, except that it has become a convention or a custom name of a foreigner. The translation should be based on the principle of being unambiguous and not being confused with the context in principle. However, Fortress Besieged often uses ambiguous transliteration words to produce humorous effects for ironic purposes. Such as:

The poem follows the source of the poem, what Li Yishan, T.S. Eliot, Tristan Corbie, Leopardi, Franz Werfel) poems have. [1]

This sentence is the so-called "poet" Cao Yulang masterpiece annotation, is the name of several foreign poets. Originally quoted foreigners only need to press the pronunciation transliteration on it, and no specific real meaning, does not reflect the author's personal subjective attitude. However, in order to achieve the irony that Cao Yuanyan does not foul, artful and humorous effect, the author deliberately chooses T.S. Eliot, Tristan Corbie, Leopardi, (Franz Werfel) these words to translate names. Because most of these words contain derogatory meanings in Chinese, and after being reorganized by Mr. Qian, the derogatory sense becomes more obvious, giving readers an impression of vulgarity, humbleness and obsession with the appearance of a sense of humor, but in fact ironic means strong, mercilessly ridiculed Cao Yulang borrowed as the name of new poetry, blindly worshiping behavior. (2) Words collocation unfamiliar

Words collocation Defamiliarization refers to the use of word break rules together, with novel or even conflict, the formation of a strange new language effect, so that readers get an aesthetic 
enjoyment. A large number of novel languages in "Fortress Besieged", the surface appears to be very surprising, exquisite taste but subtle floating, sensible and reasonable, showing the artistic charm of literary language. "The special feature of literary language lies in its defamiliarization of everyday language through a variety of ways (such as strengthening, condensing, twisting, stretching, shortening, reversing its position, etc.), which is the source of literary language." [2] Such as:

The widow had something called "Afun,' 'and the drops of honey in his voice.

It is logically untrue that the widowhood in Suzhou is described as a charming voice of a widow in Suzhou. However, judging from artistic expression, hearing, sight and taste are all interlinked, as if a widow is flirtatious and sentimental in front of readers.

Fang Hongjian to see Miss Su do not laugh when his face is also attached to a smile, curl the air after the music stops as the sound.

Here the face and smile with "attachment" link, very novel, and the use of curl as a metaphor, the author intends to visual and audit access, enhance language appeal and express flexibility to form a fresh, profound feeling, giving unlimited Reverie.

The girl was old, dressed in a rainbow of colors on her face after the rain, under the prisms of the sun, or blooming gardens.

In this sentence, the author uses the colorful things like Rainy Rain, Triangular Sunlight and Colorful Blossoming Gardens to make a girl's face look like a figment of imagination. It guides the reader to imagine that piece Vulgar and funny face, contrasting with the vulgar, ugly style that girls would like to dress without being dressed up.

The entire work of "Fortress Besieged" is full of the witty sense of "ridicule", but most of them belong to the "philosophical" style of humor. They make people understand the profound truth in laughter and feel the author's love and hate. This witty humor no vulgar gas, giving a sense of intimacy and comfort.

Someone called him (Miss Po) the cooked meat shop, because only the cooked meat shop will display many warm colors of meat on the public display, and some call him "truth" because it is said that "the truth is naked," Miss Bao and Not undone, so they are amended to be "partial truths."

Here to think that when one is dressed up, foreign women's clothing is called "Cooked meat shop," "Local Truth," the expression of the absurd taste of Miss Bao ridiculed joke, so novel and witty metaphor, although it is ridiculous, But savor but interesting.

Hong gradually rummaged for a long time, actually found a Chinese translation of the "ethics outline", borrowed back to the room, a great Tang Sancang get the Buddhist scriptures back to Changan happy.

Under the condition of such a poor teaching equipment such as Sanlv University, a reference book was found, and the other party's joy was no less than that of the Tang Sanzang who had taken Buddhism back to Chang'an. Let readers truly feel the joy of Fang Hongli's finding of the book in the laughter, and at the same time reminiscent of the social status quo of poor education resources at that time, showing real social reality in the face of laughter.

The humor in "Fortress Besieged" often makes people feel bitter and helpless in laughter. There is a serious irony, but its presentation is humorous and funny. It can be said that the author is using comedy and comedy Sexual language to write a tragedy, a combination of serious and absurd. Such as:

Hong gradually get attack on both sides, I learned the importance of study diploma. This diploma, as if Adam, Eve, the role of lower body leaves that can be ashamed package ugly; a small piece of paper to a person empty, lonely, stupid are covered up.

Here is the use of Adam and Eve in the Western Bible to hide the ugly with leaves. It mocked the student life and human nature headed by Fang Hong-jia, comparing "a diploma" with "a fig leaf." In the seemingly humorous joking behind the literal also make people appreciate the deep connotation: after the Opium War, China was forced to connect with the world, the ancient civilization of the Chinese nation and the Western civilization began an unprecedented clash, collision, conflict and even meet, Integration, prominence of social conflicts, numbness of human nature and ugliness are 
all manifestations of this phenomenon among some foreign students led by Fang Hongjian. In the superficial humorous language, the author wrote about the emptiness and barrenness of the Chinese people's spiritual world at that time, which reflected Qian's artistic attainments of writing tragedies in the form of comedies.

\section{3. "Fortress Besieged" humorous language skills}

The humor formed by the phonetic elements refers to the humorous effect obtained from the variation by deliberately integrating the original programs and norms of phonetic or phonetic sounds through the comprehensive application of sound, rhyme, tone and other factors or punctuation in the communication of discourse. Ambiguous transliteration, double homonym, rhyme and other phonetic meanings in "Fortress Besieged" form a humorous expression.

Ambiguity transliteration is the use of the characteristics of Chinese pronunciation associated with pronunciation of other languages, the pronunciation of the same or similar relationship, the semantic differences in the two languages intended to cause ambiguity, the formation of misunderstanding, and then give rise to a humorous effect. Mr. Qian's skillful use of ambiguous transliteration in "Fortress Besieged" translates the purely objective transliteration of transliteration into a writer's subjective feelings, which not only adds to the readability and taste of the text but also creates a satirical and humorous expression Effect, we can say that this means "Fortress Besieged" this work's unique humorous skills. Such as:

Xinmei fiercely bit his lip because he thought "Mating" was more homophonic with "Mei Ting".

Here in order to curse Li Mei Ting happy, using the transliteration of word ambiguity means, the "Mei Ting" replaced by homonym but not synonymous "Mating." "Mating" expresses the meaning of "mate" in English. "Mating" and "Mei Ting" have the same pronunciation but convey different meanings, which reflect the beauty of homonymy. The author uses only one sentence to concisely and vividly cursed Li Meiting, revealing a scholarly "mockery" between the lines.

Homophonic pun is the use of the same word, take care of two different things, the expression of two meanings, expand the meaning of the surface to explore its deep meaning, the greater the difference between superficial meaning and deep meaning, the more humorous color, the comedy effect The more obvious. Mr. Qian Zhongshu use Chinese homophonic pun, enhance the expressive power of language, making the characters interesting, lively. Such as:

"He did not read the book? He gave a woman dizzy head, no conscience, he did not want to rely on the cultivation of the Zhou family, what 'Miss Miss' Miss Candy' will fancy him!" Mrs. Zhou Do not know Miss Hong understanding gradually Miss, she because of "sesame candy," that ready-made nouns, said "crisp" Shun mouth with the "sugar"; letter nonsense, and partial to the word, the world is unknown prophets prophecy are Such.

"Su" and "crisp" homophones, "Tang" and "sugar" homonym. Mrs. Zhou called Miss Su a "Miss Cristi," and she accidentally came up with a "Miss Sugar" because of the word "Sesame Crisp" which she remembered, showing the punchline of "Sesame Crisp, Crafted a "sesame candy," it can point out the two women and Fang Hongjian related, very humorous effect, but also makes the characters lively and full of fun.

In the translation of foreign poems, Fortress Besieged emphasizes the Chinese appearance of foreign poems, which is manifested in the translated "translated rhyme". The use of rhyme enhances the musical beauty and rhythm of language. Such as:

Miss Baoxiang a bunch of waist, is the "Arabian Nights" in the praise of the Arab poet praised beauty conditions: "thin body, heavy at the back, standing sore waist and limbs."

The "heavy" and "painful" rhymes and rhymed feet reflect the character of Miss Bao's body. The image of a woman with "thin waist and fat buttocks" is vivid and the syllables are tidy. In order to colloquialize the language, Qian deliberately translated the translation into a vulgar or even vulgar one, which is quite appropriate to describe the vulgar person as Miss Bao and more in line with other boat guests who appreciate the rich local "partial truth" of Miss Bao Tone. The use of rhyme enhances the beauty of language and music while successfully creating a ridiculous image of the beautician for the reader while creating a humorous atmosphere that meets the humorous language 
style of the entire work.

\section{The Use of Grammatical Means to Form a sense of Humor}

In order to achieve a humorous expression, the use of words in "Fortress Besieged" boldly breaks through the norms of words, especially the conventions of idioms, which not only makes the language humorous and interesting, but also makes the expressions more concrete and definite. In the Dictionary of Rhetoric, it is said that the idioms are used flexibly, and some are used to adjust the rhythm and coordinate the rhythm; others add more semantics and change color to make the language more vivid and vivid [5].

Morpheme substitution means that in order to make the language use new ideas, intends to break the use of the original language norms, replace some of the original words in the morpheme, flexible imitation of some new words, the form still remain similar to the original words or The same structural features, content has been given a new meaning. Such as:

Hong sighed ... If the next big teens, to the age of return, maybe love will be silly as mad, the old man love to hear like the old house with a fire, it is not saved.

Here is based on the principle of synonymous, the use of analogy in the language of the mechanism, the "crazy" of "crazy" the morpheme, replaced by "silly" and got a similar to "crazy" new Language composition "silly as crazy", the words become popular and humorous witty.

Really worried when the poor, people are poor and poor, lies are not good.

Here to replace the conventional phrase "people are poor and short" to "short and poor people," not only the replacement of morpheme, "Chi" and "Chi" itself is homophonic. After the replacement, "lies are not good," "Chi short" semantically more coherent, more humorous and humorous.

"Word sequence change" refers to the use of words in order to meet the needs of the expression, the words within the temporary change of position of the morpheme to form a new language component, resulting in a new meaning or new taste. Such as:

Two o'clock in the afternoon, the two came back, drooped, exhausted, said the primary and secondary schools were evacuated to the countryside, did not find anyone, "eat again, you are hungry."

"Droop and funeral" originated from the replacement of the order of "Dejected Depreciation". After the exchange, the combination of two verb-object structures turned into a union of two verbs and verbs. The "head" and "qi" in "Dejected Depression" are the objects of "Depression" and "Funeral" which are the objects of domination. However, the "head" and "qi" of "drooling" are the originators of the two actions of "droop" and "funeral", becoming the subject. By adjusting the order of "dejected", the object becomes the subject, passively becomes active, and the action of the table becomes a description of a state, which is also coordinated with the "exhausted" below.

Simplification is based on the original words, the morpheme to streamline and compress. The method of operation is generally to follow the principle of standardization under the premise of the deletion or compression of some of the elements of the word to simplify the traditional and enhance the effect of expression. Such as:

He wanted to criticize Peng Peng good move right and wrong, but in front of Mrs. Peng Tou's face, so did not say it.

The "moving right and wrong" here is a simplification of "telling nonsense." This simplification has increased the intensity of "moving" so that "moving" can be more visualized. This makes the reader feel "yes" and "non" as the goods are generally moved to get away, easy and comfortable. This figurative language is witty and witty, vividly and vividly showing the irony and humorous taste of Fang Hongjian's words, and expresses Fang Hongjian's resentment toward his brother.

\section{Using Rhetorical Means to Form Humor}

Metaphor is "an important means of language visualization." [6] It is also an important way of language humor. The structure of the metaphor is rich, and the ways of creating a humorous metaphor are varied. Among the more than 250,000 words in "Fortress Besieged" manuscripts, 
witty and profound metaphors abound in "Fortress Besieged," with as many as 500, not only in quantity but also in novel images and humorous. Such as:

As if she had grabbed a rope from Che-hung and tried her best to pull her head, and when the rope was about to break, she took a few steps and the rope softened.

Here with an image of the metaphor for our portrayal of a common quarrel in the field of life painting. To a very common daily routine "to grab the rope" as a vivid image of Fang Hongjian and Sun Roujia quarrel scene: the two often quarrel and each other, but each to Hong gradually infuriating, soft Jia It will take the initiative to make concessions to ease the relationship between the two sides, metaphorically both images and humor.

The five sausages she had in her hand were very sensitive. They caught a louse in her hair and strangled her.

Here the "five sausages," the analogy image of the innocent innocent hotel proprietress, five finger short as five sausages in general, the boss's degree of obesity from the "five sausages" can be seen.

Hung gradually unable to refuse to kiss her face back. ... just as if the Qing dynasty had a cup of tea on the side of a tea delivery boy or the lips of the witness in the old court touched the Bible at most, just as the faithful kisses the Living Buddha of Tibet or the Pope Big toe, a close at arm's length.

Here, Mr. Qian Zhongshu used three metaphors to describe the attitude of Fang Hong gradually returning to kiss Miss Su, especially the last one, extremely ridiculous. Let readers also deeply appreciate this Miss Su's own initiative to kiss is how light, indicating that Fang Hongjian really do not like Miss Su, just flirting, but Su Wen Zan's own passion, but also to make Fang Hongjian Helpless.

Exaggeration is to highlight some of the ideas, feelings, deliberately exaggerated, objective or things to do exaggerated or narrow description. In addition to the exaggeration can produce magnificent style effects, but also can be used to create a humorous effect. Qian Zhongshu familiar with exaggerated features, in a humorous atmosphere, the object will be exaggerated to the extreme. Such as:

Hung-cheng's blush is like a cold and hot patient with 103 degrees.

Here Fang Hongjian's facial hair is exaggerated to the extent of 103 degrees, can be said to be the extreme heat, showing in front of readers because of lying and blush embarrassment, banter irony means full.

Fang Hongjian busy said that dishes are good, eat even the tongue eaten.

It is obvious that Fang Hongjian deliberately exaggerated his intention to praise Mrs. Wang's taste for good home cooking and fully demonstrated Fang Hongjian's eloquence and image.

Irony is to say the opposite, that is, verbally, the literal meaning and ideological cover actually the opposite of the meaning to be expressed, divided into satirical irony and pleasant irony two. Ironically, Ironically, Fortress Besieged also creates a humorous language. Such as:

Dispensers to write off the table sitting next to a fat woman frankly spread the white and not the chest, feeding children milk, milk is the child's meal, so it should eat in the canteen, proving this hotel is managed by the science. She filled with fatty nutrition, children think it is sugar melted lard.

Here the author uses "fat women spread their breasts in the canteen to feed their children," satirizing the management chaos in "Eurasia Grand Hotel," "Eurasia Grand Hotel" can be said that the world situation and the microcosm of Chinese society in the humor Behind the language, what is hidden behind is the sour heart of the country when the nation is weak and chaotic. Reflects Qian Zhongshu first cold humorous style.

\section{Conclusion}

Humor is the essence of language. The use of humorous language not only enhances the fun of the article and the expressiveness of language, but also gives us abundant knowledge and profound reflection. "Fortress Besieged" is a model of the combination of Western novels and Chinese classical novels. The humorous language in the text flashes the light of the author's knowledge and 
wisdom. The novel is innovated in language. The author uses phonetics, grammar, rhetoric, Habitat and other elements of non-conventional methods to expand the tension of language performance, the formation of a humorous wit and fun humorous world of art.

\section{References}

[1] Qian Zhongshu. Fortress Besieged [M]. Beijing: Joint Publishing, 2002.

[2] Ma Xinuo history of Western literary history [M] Beijing: Higher Education Publishing, 2002: P386

[3] Hegel Aesthetics: Volume 2 [M], translated by Zhu Guangqian. Beijing: The Commercial Press, 1979: P132.

[4] Wu Shiliang, Phonological Elements and Humorous Speech [J]. Language and Translation, 2000: P58.

[5] Wang Dechun Rhetoric Dictionary [M]. Zhejiang Education Press, 1987 (5): P23.

[6] Zhang Gong. Modern Chinese rhetoric [M]. Hebei Education Press, 2014: P103. 